\title{
STUDY STUDENTS AND SPORTS ACTIVITY DURING THE STATE OF EMERGENCY DUE TO COVID - 19
}

\author{
P. Slavcheva-Hinkova*, A. Bozhkova \\ Department of Language and Sport, Sport Sector, Medical University - Sofia, Bulgaria
}

\begin{abstract}
On March 13, 2020, the government overwhelmingly supported the introduction of a State of Emergency in Bulgaria.

The country's main focus and efforts are concentrated on overcoming the infection with the new coronavirus - COVID - 19. Specialists are joining forces and based on scientific research and evidence are publishing recommendations for the best protection against the virus, the most important.

Our study is related to a survey among Bulgarian and foreign students currently pursuing different specialties at the Medical University - Sofia, to analyze how the emergency affects the habits and sports activities of students.

The tasks we set ourselves are preparation of an up-to-date questionnaire for the conditions of the emergency, with which to establish its influence on the habits and sports activity of the students, to process and analyze the data from the survey and based on the results obtained to draw necessary conclusions.

To achieve these goals and tasks, a 10 question questionnaire was developed, which was conducted online while remote learning during the Summer semester of the school, 2019/2020 with students from MU - Sofia.
\end{abstract}

Key words: survey, state of emergency, COVID-19, sports activity, students.

\section{INTRODUCTION}

On March 13, 2020, the government overwhelmingly supported the introduction of a state of emergency in Bulgaria due to the growing danger of a global pandemic with the coronavirus COVID-19. It was initially anticipated to be 1 month, from 13 March to 13 April, after which it was extended until 13 May 2020. A state of emergency is a situation in which the government of a country has the power to take action that would not normally be possible. The government can declare such a situation during a disaster, civil disobedience, or armed conflict (1). Imposing these changes in the specific situation aims to warn citizens and trigger government services to start implementing plans to tackle the coronavirus pandemic.

\footnotetext{
*Correspondence to: Petya Mitkova SlavchevaHinkova, Medical University - Sofia, Department of Language and Sport, Sport Sector, 1431, Sofia, 2 Zdrave Str., Email: p.slavcheva@deos.musofia.bg,, Mobile: +359889294769
}

The country's main focus and efforts are concentrated on overcoming the infection with the new coronavirus - COVID - 19. Specialists are joining forces and based on scientific research and evidence are publishing recommendations for the best protection against the virus, the most important of which are: "... strengthening your immune system with sleep, exercise, and good nutrition and most importantly - washing your hands and maintaining social distance to avoid infection" $(2,3)$.

The importance of communication and channels of advertising the relevant information helps with establishing a healthy, smart, and promising generation is recognized both internationally and nationally. The promotion of various food and beverages to the audience should comply with codes of ethics and norms, as well as with personal responsibility (4). 
An environmentally friendly lifestyle is increasingly significant in the dynamics today and that includes mostly a healthy diet (product selection, regiment) and physical activity. In the current pandemic situation, it becomes even more relevant. In the article "Hygiene of nutrition as a first-rate value of a healthy way of life", the author focuses on the fact that according to the latest scientific database there are many products with adverse effects on the human body as a whole. The author makes recommendations regarding the reduction of certain foods that suppress immunity, or even the cessation of their consumption. She gives a high assessment of physical activity and sports as a basic unit of a healthy lifestyle and shares the opinion that the right combination with good eating habits would contribute to the adaptation of the body to any situation (5).

A study by Angelova (2019), makes clear that the greatest contributor to the deterioration of health, according to students, is immobility, lack of conditions for sports and physical activity, and lack of healthy lifestyle culture (6). Factors underlying the present study have been studied by other authors (7).
SLAVCHEVA-HINKOVA P., et al.

Our study is related to a survey among Bulgarian and foreign students currently pursuing different specialties at the Medical University - Sofia, to analyze how the emergency affects the habits and sports activities of students.

The goals we set ourselves are:

1. Preparation of an up-to-date questionnaire for the conditions of the state of emergency, with which to establish its influence on the habits and sports activity of the students;

2. To process and analyze the data from the survey.

3. Based on the obtained results to draw the necessary conclusions.

\section{METHODS}

To achieve the goal and tasks, a questionnaire with 10 questions was developed (Appendix 1 ), which was conducted online during the distance learning during the Summer semester of the school. 2019/2020 with students from MU - Sofia. At this stage, the object of analysis is the results of the survey conducted among Bulgarian students studying at MU Sofia. In Table 1 we present information about the surveyed persons.

\section{Appendix 1 and Table 1}

\section{Appendix 1}

INTERVIEW SURVEY /COVID - 19/ ABOUT SPORTS IN
EMERGENCY CONDITIONS
This survey aims to examine students' lives and habits in the context of a state of emergency
imposed by the Coronavirus (COVID - 19)
PLEASE GIVE ONE ANSWER TO EACH QUESTION.
SEX: F/M; AGE: .......... ; COURSE: ........ ;NIVERSITY: ......... FACULTY: ...........
1. Do you comply with the measures imposed by the state of emergency, including stay at home order?
a) Yes;
b) No.
2. Do you think you're eating habits or eating frequency changed during a state of emergency?
a) Yes, I eat more;
b) Yes, I eat less;
c) Eating the same way;
3. Do you think you changed your fluid intake during an emergency?
a) Yes, I drink more;
b) Yes, I drink less;
c) I drink the same amount;
4. Do you take more vitamins, nutritional supplements, or healthier foods in order to boost your immunity
during a state of emergency?
a) Yes, I take more vitamins and supplements;
b) Yes, I eat healthier food;
c) Yes, I combine both;
d) I have not changed anything in the intake of vitamins, supplements or diet.


5. How many times a week does you exercise during an emergency?

a) Every day;

b) Once a week;

c) 3 times a week or more;

d) I have no sports activity.

6. What kind of sports activity do you do during a state of emergency?

a) Some accessible elements of ball sports;

b) Cardio exercises including the types of tourism;

c) Exercises to improve physical performance and muscle tone (fitness, Yoga, etc.)

d) Different types of dance (folk dance, modern dance, etc.);

e) I don't exercise.

7. Does social distancing and isolation affect your motivation for sports activities?

a) Yes, I have no motivation for sports;

b) Yes, I have more time and desire for home sports;

c) No, I have the usual rhythm of life.

8. When you feel anxious or stressed during the state of emergency, what do you cheer yourself up?

a) Sport;

b) Reading a book;

c) Watching television;

d) Use of mobile devices;

e) Other.

9. Do you use a mobile application to practice your sport or other home-based activity during the state of emergency?

a) Yes;

b) No;

10. Have you practiced any kind of sport before the state of emergency and what kind was it if any?

a) Power or sprint disciplines;

b) Collective sports;

c) Individual sports;

d) Martial arts;

e) Technical sports;

f) Yoga, Fitness Disciplines;

g) I have not practiced sports before the state of emergency.

THANK YOU FOR YOUR PARTICIPATION IN OUR SURVEY!

Table 1. Information about the surveyed persons

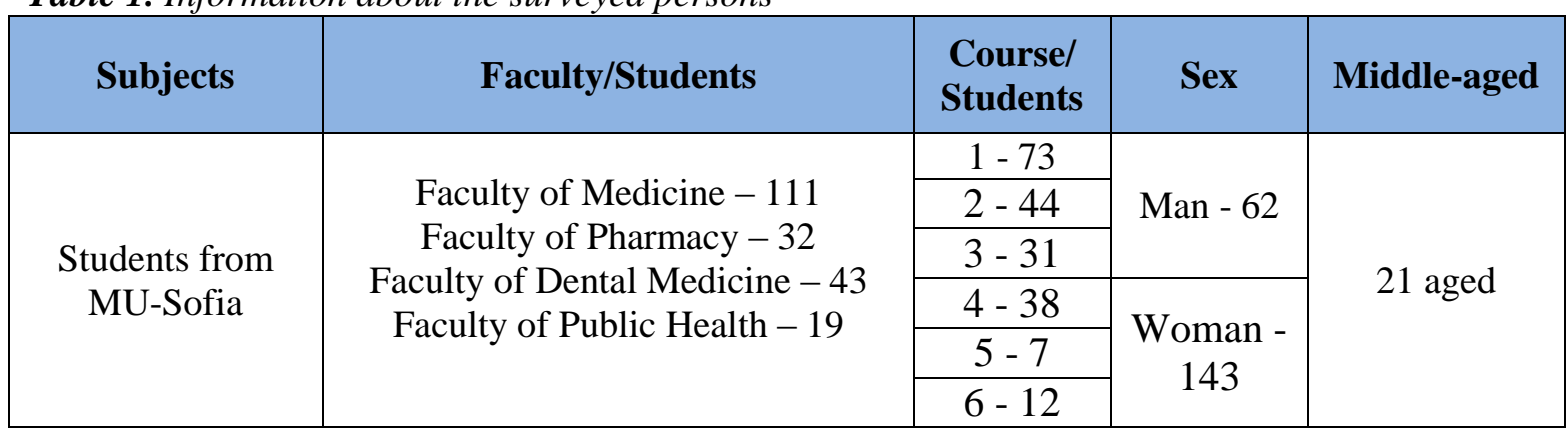

\section{RESULTS}

A total of 205 students took part in the survey. The average age is 21 years, of which 62 (30, $2 \%)$ are men and $143(69.8 \%)$ are women.

Compliance with the measures imposed by the state of emergency, which is unusual and worrying for all, given that Bulgaria was last in a state of emergency during World War II, the large percentage $(90.7 \%)$ falls on those who have stayed at home, but there is also a small percentage $(9.3 \%)$ who do not agree with the measures.

In (Figure 1) - 50.7\% of students indicated that they maintained their diet, but rather a large part of them $-35.2 \%$ said they increased their intake, and only $14.1 \%$ reduced it. These results are very indicative of how a longer stay at home leads to greater food consumption. 


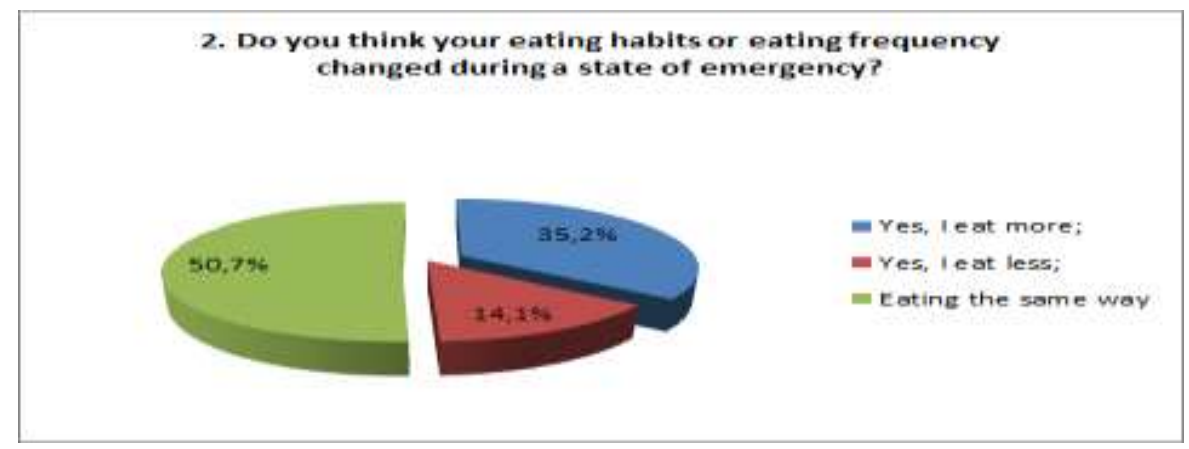

Figure 1.

Figure 2 shows that half of the participants $48.8 \%$ have not changed their habits, and $35.6 \%$ drink more fluids than usual. Only $15.6 \%$ have reduced consumption. In this figure, as in the previous one, we have very similar results, so we can draw similar conclusions. Food and fluid intake are proportional.

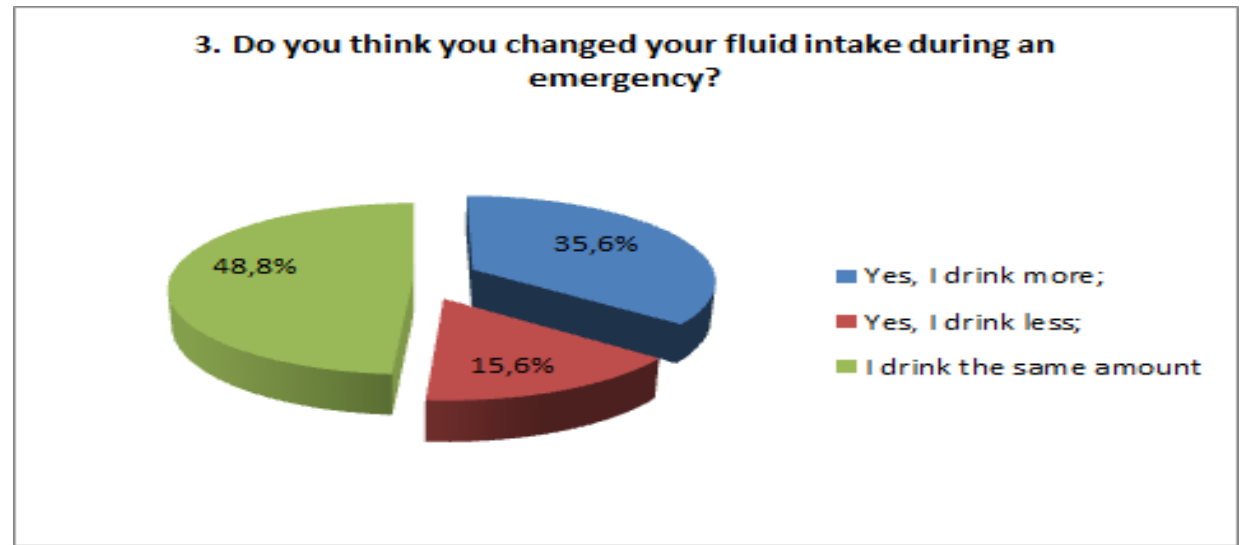

Figure 2.

One of the recommendations (of specialists) related to the epidemic is the intake of vitamins and food supplements to strengthen immunity. (Figure 3) presents the opinions of students on this issue, with the largest percentage $(42.4 \%)$ answering that they have not changed anything in their daily lives, followed by those who have complied with the recommendation and have increased their intake (26, 3\%). A small percentage eat healthier food and combine both.

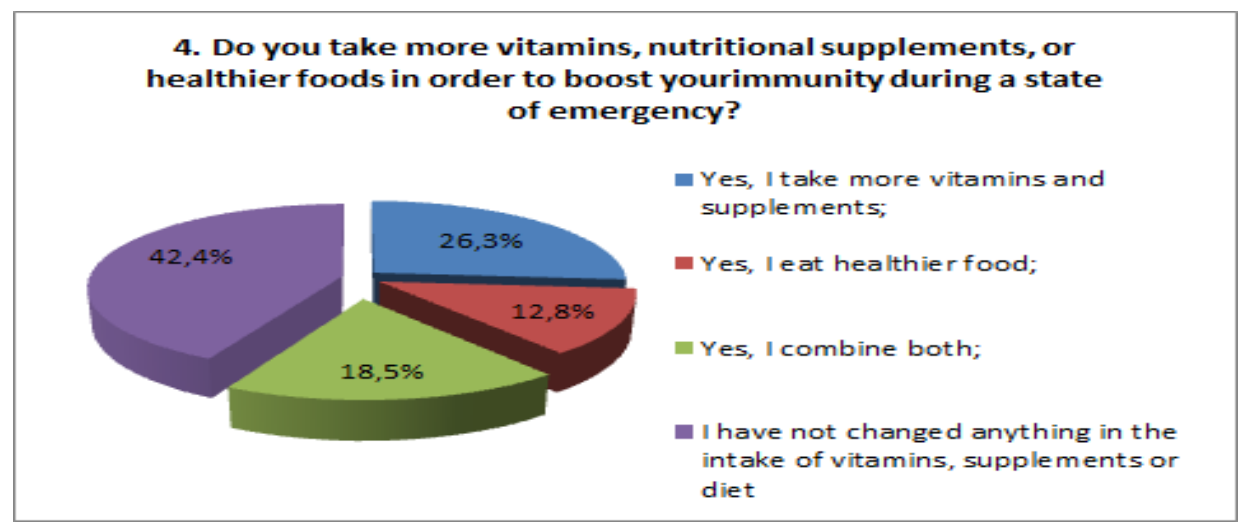

Figure 3.

Question №5 is related to physical activity. (Figure 4) shows that young people are well aware of the benefits and impact of sports and manage to exercise 3 times more and perform some kind of physical activity or 38\%, $24.4 \%$ exercise once a week, and $21 \%$ - every day. The percentage of athletes is small, $16.6 \%$, but it is worrisome that there are students like that. 
SLAVCHEVA-HINKOVA P., et al.

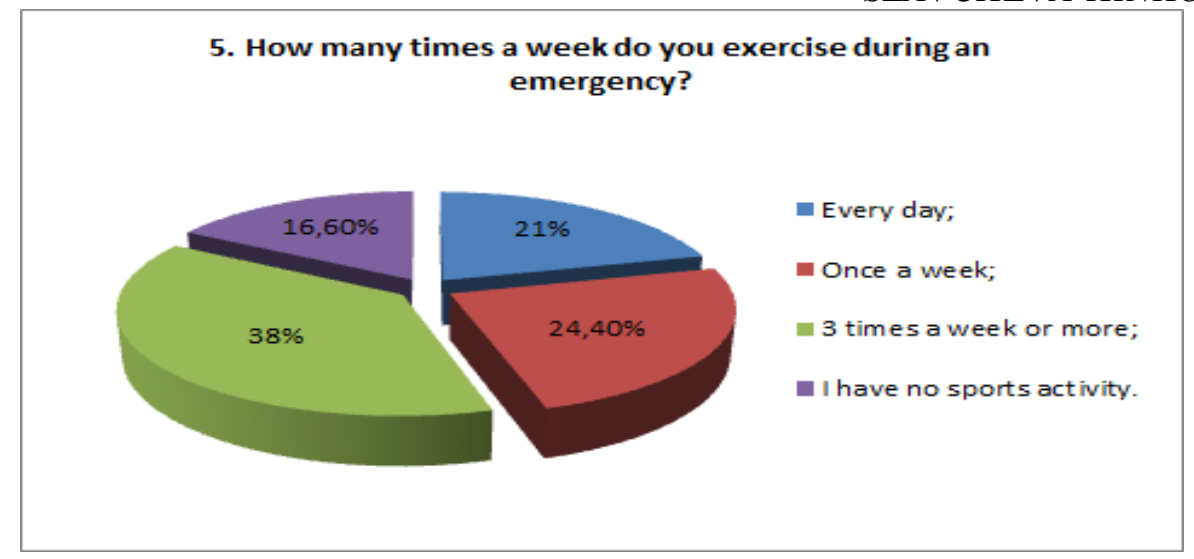

Figure 4.

From the percentage of answers to the question "What kind of sports activity do you do during the state of emergency?" the answer "Exercises to improve physical qualities and muscle tone (fitness, yoga, etc.") is given by $52,7 \%$ of the total number of respondents (Figure 5). This is due to the fact that this type of activity is most suitable for practice at home. Another sports activity, which is preferred by $18.5 \%$, is "Cardio exercises including the types of tourism". Here we think that the introduced emergency measures, as an option for sports, are important. The small percentage is worrying - $18 \%$ of young people who do not engage in any sports activity. The remaining percentages are distributed among the answers: "Some accessible elements of ball sports" and "Different types of dances." This, in our opinion, is due to the inappropriate conditions for practicing these sports and motivates us to encourage and support the desire of the students for independent sports activities.

The seventh question is "Does social isolation affect your motivation for sports?" When looking at the results, we can see similar results of two of our proposed answers - "Yes, I have no motivation for sports" (32.2\%) and "No, I have the usual rhythm of life" (28.8\%). The answer "I have more time and desire for sports at home" $(39 \%)$ prevails, which is a very pleasant surprise for us (Figure 6). The data generally shows the positive attitude and perceived benefit of the subjects from sports in an unusual setting.

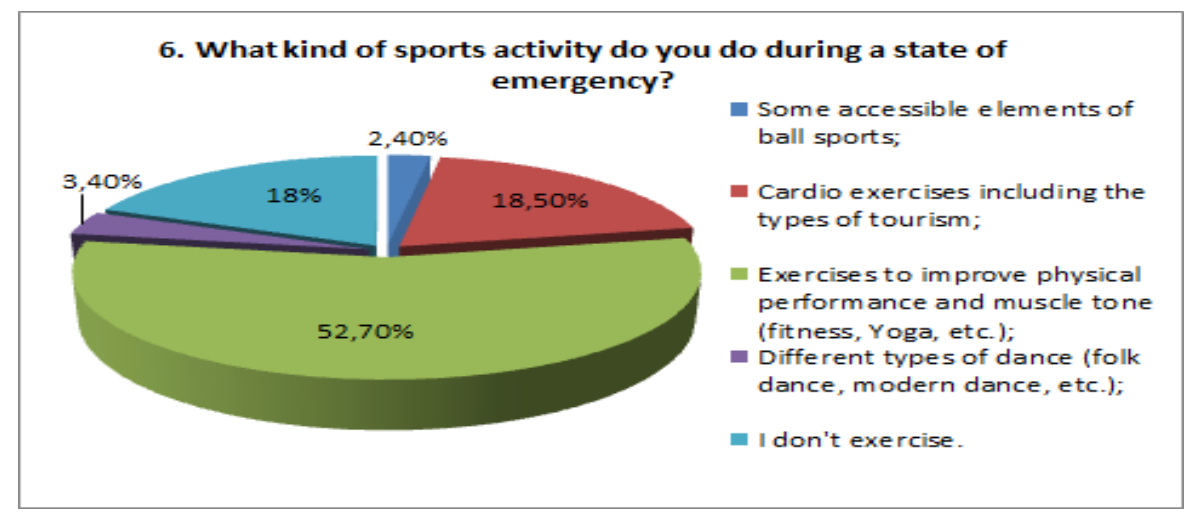

Figure 5.

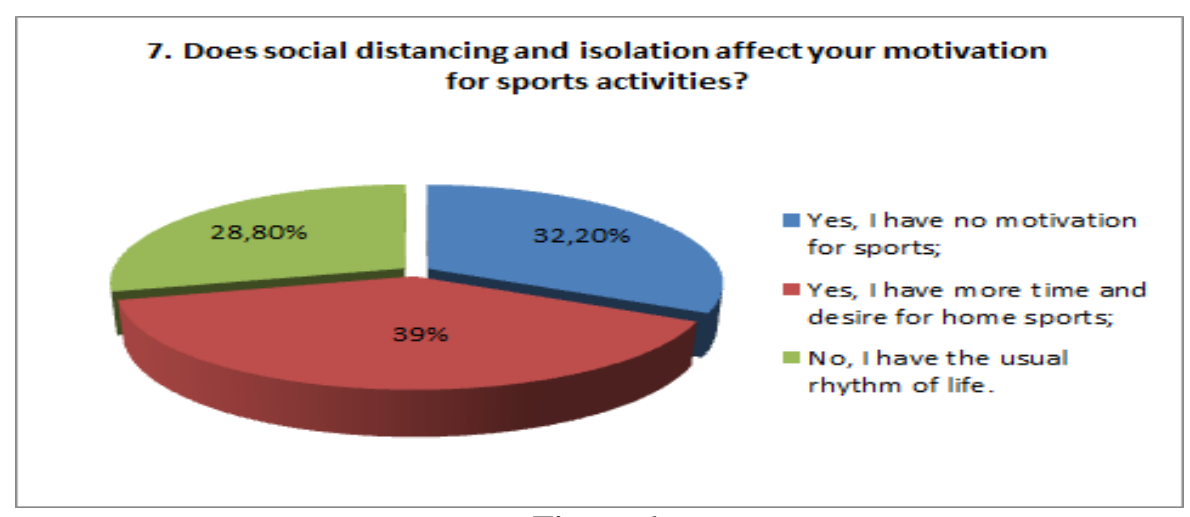

Figure 6. 
From the answers shown to the 8th question "When you feel anxious or tense during a state of emergency, what do you cheer yourself up with?" It is clear that a large group (29.9\%) cheer up doing art, $25.9 \%$ of young people cheer up by engaging in sports activities, which shows the positive impact of sport in quarantine and the need to practice it. "Reading a book" is the preferred answer by $16.6 \%$ of respondents and $13.2 \%$ say that watching TV calms them down. The other answers are few and far in between and they are not indicative in the current study - talking to a friend, listening to music, gardening, not feeling worried, cooking.

The answers to the question "Do you use a mobile application to practice your favourite sport or another type of physical activity at home during the state of emergency?" allow us to a large extent to understand the students' views on this topic. There is a high percentage - 57.6\% of those who answered "No", while $42.4 \%$ answered "Yes". We assume that the lack of a teacher/coach to guide the process, as well as the social element in sports, have a leading influence on the distribution of these answers.

The data obtained from the last question "Did you practice any kind of sport and what kind before the state of emergency?" reflects the prior interest of students for sport activities. The answers are the following - $41.5 \%$ for "Yoga and fitness disciplines", which in our opinion is due to the larger number of girls who took part in the survey. $19.5 \%$ of the students indicate individual sports and $18 \%$ team sports, the remaining $6.9 \%$ are distributed among the other proposed sports, which do not appear to be very popular among the students from MU - Sofia. The surprisingly low result of $14.1 \%$ who have answered "I have not practiced sports before the state of emergency" is commendable.

\section{CONCLUSIONS}

Social isolation has a significant impact on people in these conditions and especially on young people who are accustomed to a very dynamic and dense everyday life, without ignoring the fact that these are future medical professionals who will work on "the first line". In conclusion, we can summarize:

1. Students try to maintain their eating habits and consider it necessary to engage in sports and activities available to them,
SLAVCHEVA-HINKOVA P., et al. although there are no normal conditions for these activities during the quarantine.

2. Sport has an important role, both for a stable physical condition and for a better emotional state.

3. We, as teachers and sports professionals, need to be better prepared for such situations, to meet the needs and requirements of the sports activities of our students.

ACKNOWLEDGMENTS: Thanks to all students from the Medical University Sofia who expressed a desire to participate in this study.

\section{REFERENCES}

1. https://bg.wikipedia - 12.04.2020.

2. Tashkova, R. How does the pandemic affect our psyche and how to take care of it? Bulgarian Science Journal. Special issue dedicated to Kovid-19, ISSN: 1314-1031, April, 2020, 56-59, https://image.nauka.bg/magazine/BGNauka-COVID-19.pdf, 2020.

3. Todorov, R. Here's how your immune system reacts to Covid-19. Bulgarian Science Journal. Special issue dedicated to Kovid-19, ISSN: 1314-1031, April, 2020, 46-50,

https://image.nauka.bg/magazine/BGNauka-COVID-19.pdf, 2020.

4. Sidjimova, D. Potential of advertising for education of the principles of healthy eating. Sat. Scientific conference with international participation ,Aging, health, geriatric care“, ISBN 978-954-338-141-8, pp. 321-324, 2017.

5. Taneva, S. Hygiene of nutrition as a firstrate value of healthy way of life. $X$ International scientific-practical online conference./ed. S.T. Kokhan. - Chita, ISBN: 978-5-9293-1883-2, pp. 218-226, 2019.

6. Angelova, P. Ascertainment of risk factors negatively influencing on the health of students rehabilitators. Health Policy and Management Journal, Vol. 19, №2, pp. 5659, ISSN 1313-4981, 2019.

7. Dyakova, G., Sinilkova, M., Popova, M., Petkov P. Physical education manual (for organized and stand-alone exercises). ISBN 978-954-338-031-2, Ac. ed. TrU, 2012. 